\title{
LA FECH EN LA BÚSQUEDA DE LA MASIVIDAD Y LAS TRANSFORMACIONES SOCIALES
}

\author{
NICOLÁS GRAU*
}

A Salvador Allende, el Presidente de los jóvenes, que no en vano pronunció el discurso de triunfo de su candidatura a la Presidencia de la República, desde el balcón de la Casa de la Federación de Estudiantes de Chile

La historia de la FECH debiera ser escrita a la luz de su incidencia en la sociedad, su participación en las transformaciones reales del país y la Universidad. Ya que, como tantas otras organizaciones sociales, su relevancia y posibilidad de seguir existiendo no se juegan en el impacto que tiene sobre la vida de los que participan en la Federación; la necesidad de su existencia se mide en su efectividad de viabilizar los sueños de los estudiantes, desde los más simples y cotidianos, hasta los más trascendentales, los ideológicos.

Sus grandes crisis y auges pueden ser explicados bajo el prisma de la capacidad efectiva de incidir en la política del país, idea que en adelante será resumida como "incidencia". La FECH, incluso, ha sido tomada por los estudiantes y clausurada por estos mismos. Al respecto, mi impresión es que los jóvenes no somos leales a las instituciones per se; nuestro compromiso y rebeldía están ceñidos a la incidencia. La organización política está en constante evaluación y comparación con las ventajas que permite el individualismo a la hora de mejorar nuestras vidas. En este sentido, podemos decir que la validación de la FECH es una pugna constante entre distintas estrategias para producir realidades que nos hagan más felices.

* Presidente de la FECH, periodo 2005-2006. 
En honor a la economía de las palabras y evitando explicaciones dificultosas, debiera resumir lo anterior diciendo que la $\mathrm{FECH}$ es simplemente un instrumento, evaluable considerando objetivos distintos a su existencia, pero después de casi un año de trabajar en su directiva no puedo expresarme en estos términos. A la luz de mi experiencia no estoy dispuesto a semejante nivel de racionalidad política.

\section{La FECH actual...}

La actualidad de la Federación está profundamente marcada y limitada por las características generales de la política nacional. Hoy vivimos en un país donde los sujetos son mucho más contempladores de lo que pasa en sus vidas que constructores, existe un bajo nivel de politización de la ciudadanía. El exiguo poder local y social contrasta con la preponderancia del esquema de democracia representativa ${ }^{1}$, el cual desconfía y teme de la participación y organización de sectores particulares de la sociedad. En términos del discurso, se ha instalado en la conciencia política que el mero hecho de estar en el gobierno permite tener una visión más solidaria que se preocupa por todos, que la que podría representar un sector organizado de la sociedad, sea sindicato, federación de estudiantes, algún gremio, etc. ${ }^{2}$.

Por otro lado, el diseño institucional instaurado tras la vuelta a la democracia en los años 90 fue realizado bajo un profundo temor al poder del mundo social organizado, sector que paradójicamente fue clave para la construcción del piso político de la transición. Es decir, la democracia se reconstituyó en Chile desconociendo el rol de las organizaciones sociales en la profundización de ésta y en la identificación de injusticias y definición de estrategias de superación de tales problemas. A esto, se le debe sumar que la coalición de gobierno no ha desarrollado un programa que revierta

${ }^{1}$ Decimos representativa en oposición a participativa. Tal conceptualización en ningún caso desea obviar la crisis de legitimidad que tiene nuestra democracia, la cual inhibe la "representación" de todos los sectores políticos.

${ }^{2}$ En las movilizaciones del 2005, el Ministro de Educación, Sergio Bitar, pretendió y en alguna medida lo logtó, instalar la idea de que los universitarios del Consejo de Rectores éramos egoístas. Pues al oponernos a la entrada de los bancos al financiamiento de créditos de estudios no pensábamos en los estudiantes que en la actualidad no tienen crédito. Tal punto de vista desconoce que nuestra principal diferencia era que nosotros no compartíamos en el plano ético la entrada del mundo privado y del negocio al financiamiento universitario. 
los cambios revolucionarios que realizó la dictadura en el plano económicosocial, la Concertación ha sido un gobierno, de 16 años, que ha privilegiado sistemáticamente la gobernabilidad a la justicia social.

Resumiendo el contexto, podemos decir que el quehacer actual de la FECH se desarrolla en un marco donde el espacio político de las organizaciones sociales está en crisis. Por un lado, el diseño de la democracia representativa no contempla un rol para las organizaciones sociales en la definición y desarrollo de las transformaciones relevantes del país. Por otro lado, no ha existido un cuestionamiento político de los aspectos fundamentales que determinó la dictadura, a saber, vivimos en democracia, pero en nuestra forma de vivir, sus características principales, fueron definidas en dictadura.

Aún en el marco de esta crisis general, la FECH ha sido a lo largo de estos 16 años, en particular desde el 95 hasta ahora, junto con las otras organizaciones estudiantiles, unos de los pocos actores capaces de tener algún nivel de incidencia. En el plano interno de la Universidad, los estudiantes, a través de su Federación, han sido capaces de llevar a cabo un proceso de democratización y modernización de la Universidad, tal proceso ha tendido a revertir los aspectos fundamentales de la contrarreforma que se llevara a cabo en los años de dictadura. Esta apuesta de los estudiantes, de la cual se hizo parte la comunidad en su conjunto, tuvo como principal logro los nuevos estatutos de la Universidad, en los cuales destaca el Senado Universitario, órgano que permite que en la definición del proyecto de largo plazo de la Universidad, su capacidad de pensarse a si misma, participen los diversos actores de la comunidad universitaria.

En el plano externo, el movimiento estudiantil, y en particular nuestra Federación, ha librado una lucha sistemática contra la privatización y falta de diseño del sistema universitario chileno. El cual ha tenido como estrategia de desarrollo la ampliación de la cobertura a costa de la calidad y del descalce entre los sueños de movilidad social que ofrece el sistema y lo que podrá lograr efectivamente. Es decir, en la educación terciaria se ha ido produciendo un fenómeno análogo al vivido por los ciclos educativos anteriores, a saber, la desigualdad de oportunidades se va desplazando paulatinamente desde el acceso, a la calidad y pertinencia del 
establecimiento educacional a los cuales tienen acceso las distintas clases sociales del país.

Esta batalla ha tenido como principal dificultad la elitización de la educación pública terciaria ${ }^{3}$ ya que la proliferación de universidades sin un mayor control de calidad ha permitido a los sectores sociales de menores ingresos, muchos de ellos la primera generación en sus familias, acceder a la universidad. A pesar que en términos analíticos aquello no debiera significar una mayor contradicción, ya que la lucha de los estudiantes pertenecientes a las universidades del consejo de rectores no ha sido por mantener la cantidad de estudiantes estables sino contra la mercantilización e irracionalidad del diseño del sistema educación superior; tal diferencia ha traído consigo una serie de dificultades prácticas, de confianza y coordinación política; las cuales no han permitido una articulación a política a la altura de las crisis del sistema educativo.

Aún no habiendo dado solución a la incapacidad del movimiento estudiantil de responder de manera comprensiva al nuevo ${ }^{4}$ orden de la educación superior, el año 2005 las federaciones del consejo de rectores han sido capaces, por primera vez en los gobiernos de la concertación, de avanzar en el compromiso del estado con el financiamiento público de los estudiantes de estas casas de estudios. A pesar de no haber logrado la postura de arancel diferenciado se ha avanzado en el nivel de subsidio que da el estado a cada estudiante de los quintiles más pobres y, en un plano más político, se ha demostrado que la mezcla de organización estudiantil unitaria y nacional, junto con la capacidad de proponer políticas públicas permite al mundo social no solo detener diversos procesos de deterioro del rol del estado sino que se puede avanzar en la construcción de un orden más justo y que repare las diferencias sociales que tienen como origen las estructuras de la sociedad actual.

En síntesis, creo que la FECH y el movimiento estudiantil en general han sido capaces de lograr ciertos avances y empoderamiento de los estudiantes a través de sus organizaciones, como productos de

${ }^{3}$ Esto no es cierto en todas las universidades; de hecho, dista bastante de la realidad de muchas universidades regionales. Sin embargo, la aseveración tiene una validez absoluta para la Universidad de Chile y la Universidad Católica, ambas trascendentales en la formación de los "líderes de la nación".

${ }^{4}$ Nuevo y masivo, pero que mantiene la desigualdad de oportunidades. 
transformaciones de la realidad tanto universitaria como nacional, esto en un contexto donde el espacio político de las organizaciones sociales ha estado en crisis. En particular, cabe resaltar la diametral diferencia y el proceso político que permitió el cambio de los estatutos de la Universidad de Chile cambio participativo en el cual la comunidad fue el actor central y el nivel de discusión y participación social del supuesto cambio constitucional realizado en el gobierno del Presidente Lagos. Los resultados son clarificadores, mientras un proceso tiene amplia legitimidad en su campo de acción, la Universidad; en el otro, muy poca gente cree que la Constitución del país efectivamente fue cambiada.

\section{FECH DEL FUTURO...}

A la hora de tratar de aventurar la incidencia que tendrá la FECH en el futuro, me parece importante tratar de avizorar cual será, más bien el que a mi me gustaría que fuera, el programa político de la FECH, las contradicciones que pretenderá enfrentar y, por otro lado, resulta importante hacer conjeturas respecto a la evolución del contexto de la política nacional.

Dado los acontecimientos de mayo, la revolución de los pingüinos, y la trascendencia que ha tenido y tendrá para el contexto nacional este levantamiento social, creo que resulta más pertinente discutir este nuevo marco antes de las variaciones programáticas que debiera abordar la FECH.

La movilización conducida e impulsada por los secundarios, que en su fase final (la que reparo en los aspectos estructurales de la educación) sumo a diversos actores sociales de la educación ${ }^{5}$, logro por primera vez en los años de la democracia unir la masividad del movimiento con el levantamicnto de demandas estructurales. Aquello que permitió lograr a nivel de la sociedad en general una hegemonía moral respecto a la necesidad de transformar los aspectos estructurales de la educación heredados, como toda la estructura económica y social, desde la dictadura.

Este cambio de escenario, que hoy nos permite tener un piso político para las transformaciones estructurales, da señales extremadamente claras respecto al rol de las organizaciones sociales en la política chilena, en

${ }^{5} \mathrm{~A}$ las tomas y paros de liceos y colegios, se sumaron universitarios con iguales recursos de presión. A su vez, el gremio de los profesores adhirió a las dos jornadas nacionales de paro convocadas por el movimiento secundario. 
alguna medida resuelve su crisis de incidencia. Desde los logros de este movimiento podemos estar seguros de que la organización de los sectores sociales puede producir cambios de escenarios políticos de una manera que le poder formal (gobierno y parlamento) no están en condiciones de hacer $^{6}$. Aún cuando la firma de las leyes y la discusión final la realizarán el gobierno y el parlamento (ambos marcados por un bajo compromiso con la justicia social), los movimientos sociales pueden determinar que se discute y cual es la profundidad del debate. De hecho, hoy estamos discutiendo aspectos del sentido del proyecto educativo nacional, todos ellos definidos de manera ilegítima en dictadura, y que no han estado presentes en las definiciones programáticas de los gobiernos de la Concertación.

En este contexto, de cierta claridad y optimismo relativo al espacio político de las organizaciones sociales, mi impresión es que la FECH debe abordar una serie de nuevos desafíos políticos, basado en la confianza de que el mundo social tiene un espacio que no solo ha demostrado poder llenar de mejor manera que la política formal sino que por condiciones políticas y estructurales este es un espacio que solo puede ser llenado por un tipo de movilización social, masivo y radical.

Resulta absolutamente necesario que la FECH, en conjunto con la $\mathrm{CONFECH}^{7}$, se integran a la federación de las universidades privadas, de manera que tal como el movimiento universitario brasileño, los universitarios de Chile, frente a la irracionalidad y desigualdad del sistema de educación superior, respondamos con una organización unitaria y nacional, que vea a todos los estudiantes como iguales y que ponga el acento en superar la segmentación del sistema educativo general en un esquema que no pronuncie a la ampliación de la cobertura educacional.

En el plano interno, la FECH será la clave en fortalecer la viabilidad del proyecto de la Universidad Pública, de excelencia y compromiso con la realidad de las grandes mayorías del país. Tal viabilidad se ocupará en tres áreas: la primera, y más fundamental, será la disputa por asociar e

${ }^{6}$ Ya sea por convicción política (no los consideran necesarios) o bien por incapacidad política de llevarlos a cabo (no pueden).

${ }^{7}$ Confederación que agrupa a todas las federaciones de las universidades del Consejo de Rectores. 
influir ${ }^{8}$ desde la Universidad al proyecto de desarrollo nacional de manera tal que la Universidad de Chile sea necesaria para el futuro del país; la segunda, será la disputa por mantener y acrecentar la excelencia académica de la universidad, pues si queremos que el acceso a la elites del país sea más justo, no solo hay democratizar el acceso a la universidad sino además se debe asegurar una calidad académica que permita borrar las marcas de cuna; la tercera, será la importancia que la Universidad sea porosa a la realidad social, su aporte al país se jugará en su capacidad de captar y responder a los diversos problemas de la realidad nacional.

Por último, me parece que los aspectos fundamentales que deben constituir, y que han constituido, el quehacer de la FECH: la participación y la crítica a las estructuras sociales, presentan una complementariedad que nos permite tener una visión mucho más optimista y clara sobre el futuro. La FECH tiene como principal objetivo cuestionar los fundamentos de la sociedad, el sentido de las cosas, como organización política juvenil y en el devenir de sucesivas estructuras sociales que han determinado la desigualdad de oportunidades entre las personas, no nos queda otra que aportar al progreso de la sociedad, a la superación de esas estructuras, cada una de ellas distintas y muchas veces históricamente validadas; será el rol de la juventud a través de su organización cuestionar tal validez. A su vez, de nada servirá la institución FECH si ésta no está desbordada de estudiantes, la participación es lo que hace de la FECH una institución valiosa.

El optimismo proviene de que sabemos que cuando los jóvenes se sienten constructores de la sociedad es cuando más participan, cuando el sentido de nuestras vidas está en juego, los jóvenes jugamos por completo. La FECH seguirá validándose con los años en la medida que se construya a partir de la complementariedad de estos dos conceptos, en la medida que logre una coordinación entre nuestros sueños radicales y la participación masiva de los estudiantes.

\footnotetext{
${ }^{8}$ No basta con asociarse al paradigma de desarrollo, la universidad debe ser un actor relevante en la definición de tal paradigma.
} 